\title{
Prosthetic reconstruction using gingiva-colored ceramic agent in fixed partial restoration in a 24-year old patient
}

This article was published in the following Dove Press journal:

Clinical, Cosmetic and Investigational Dentistry

29 November 2012

Number of times this article has been viewed

\author{
Nasrin R Sadaqah' \\ Jawad Ali Abu Tair ${ }^{2}$ \\ 'Department of Prosthodontics, \\ ${ }^{2}$ Department of Oral and Maxillofacial \\ Surgery, Faculty of Dentistry, Arab \\ American University, Jenin, Palestinian \\ Territory
}

\begin{abstract}
Achieving an optimal esthetic result when replacing missing anterior teeth with a fixed partial denture can be a challenge. This is especially true when interdisciplinary treatment is needed and the patient refuses this for personal or financial reasons. Here we report a clinical case where a fixed partial denture was used to change the incisor relationship and to restore the normal tooth and gingival tissue shape, morphology, and relationship by including artificial gingiva within the fixed partial denture when the patient refused lengthy and costly multispecialty treatment options.
\end{abstract}

Keywords: gingival porcelain, fixed partial denture, diagnostic waxup, provisional restoration

\section{Introduction}

Use of gingival restoration can reduce the necessity for a surgical procedure to restore missing soft and hard tissues, thereby simplifying and reducing the time and cost of treatment. ${ }^{1}$ Artificial gingival restorations can correct maxillofacial defects, compensate for inadequate maxillomandibular relationships, and promote an air seal during speech. ${ }^{2}$ Specific planning for an artificial gingival prosthesis must be undertaken to achieve optimal results. The esthetic results tend to be significantly better if the option of artificial gingiva is the first choice than when it is used as a repair tool. ${ }^{1}$

This case report describes the treatment planning for a patient suffering from loss of soft and hard tissues after trauma accompanied by a class II division 1 malocclusal relationship, using artificial gingiva in a tooth-supported fixed prosthesis. Reconstruction of the gingival architecture was achieved with planned artificial gingival restoration without the need for a surgical or orthodontic procedure.

\section{Case report}

A 24-year-old woman presented as a new patient upon referral from her dentist to the Department of Prosthodontics, Faculty of Dentistry, Arab American University, Palestinian Territory. Her chief complaint was loss of the upper anterior teeth (maxillary right lateral incisor, maxillary left central incisor) as a result of trauma 6 months earlier, with a request to have these replaced to improve the appearance of the anterior part of her mouth (Figure 1). Written informed consent was obtained from the patient for treatment and publication of this case report.

A thorough medical and dental history was taken at the first appointment. The patient was medically fit. A comprehensive clinical and radiographic examination was then undertaken. Primary impressions using alginate (Orthoprint, Zhermark Inc, Eatontown, NJ) and wax occlusal records were taken to make articulated
Department of Prosthodontics, Faculty of Dentistry, Arab American University, Jenin, Palestinian Territory

Tel +975 99475187

Fax +97092382808

Email na_sadaqa@yahoo.com 


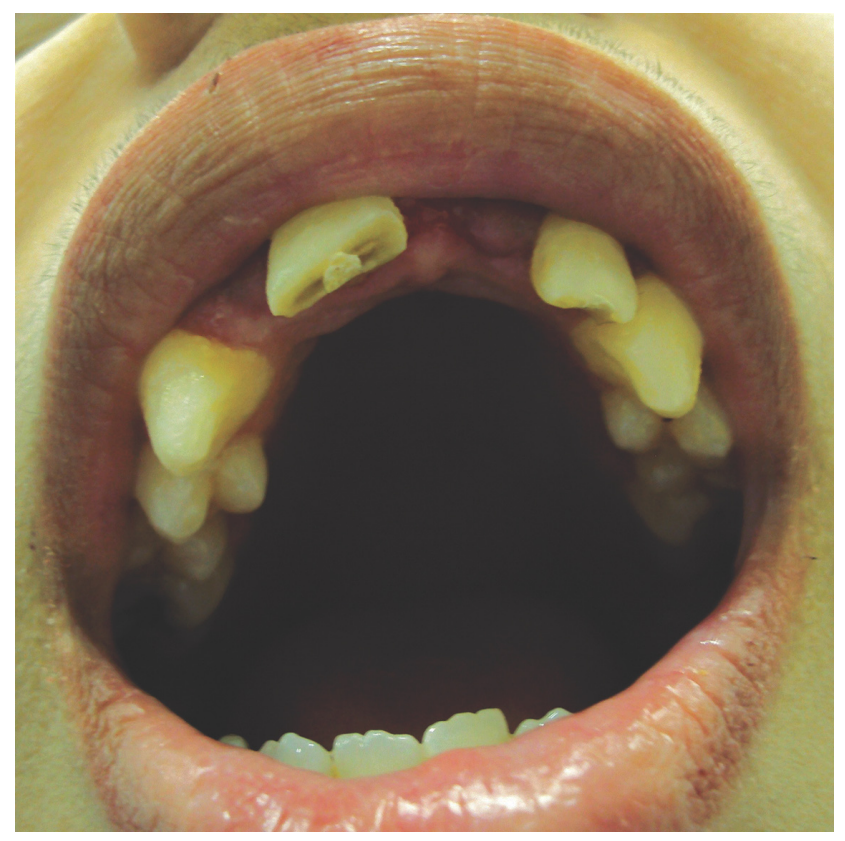

Figure I Preoperative intraoral view of missing teeth.

study models. Digital photographs were also taken. Upon intraoral examination, a class II division 1 incisor relationship with an anterior open bite and loss of vertical height in the premaxilla were diagnosed. The patient presented with a high smile line (Figure 2).

An initial discussion with the patient about the feasible treatment options, from the ideal to the least ideal choice, along with an explanation of the advantages and disadvantages of each option, was undertaken as follows:

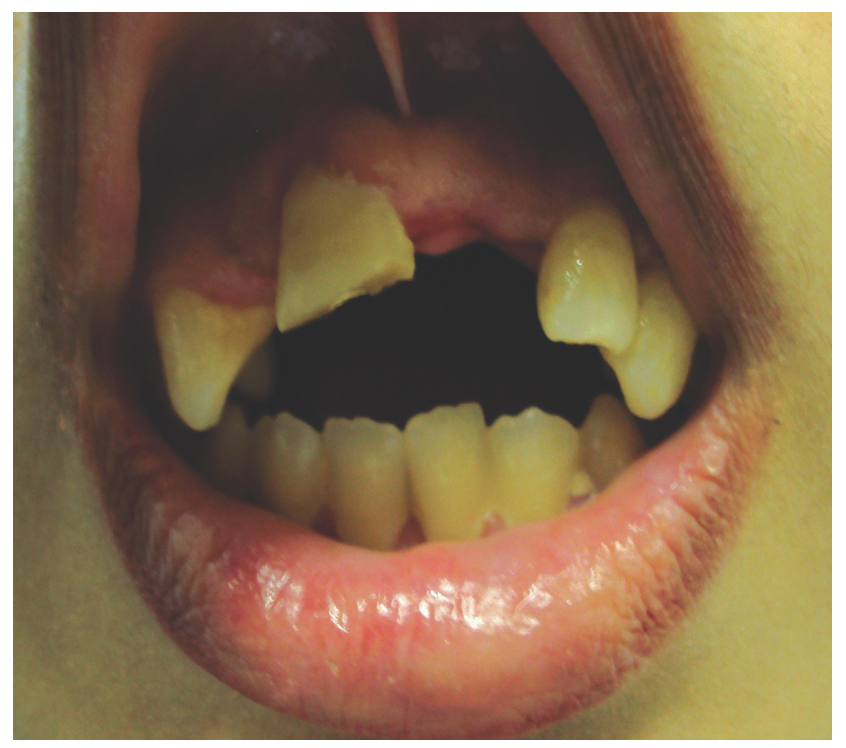

Figure 2 Preoperative intraoral view of relationship between upper and lower anterior teeth when posterior teeth are in maximum intercuspation.
- Surgical maxillary impaction followed by orthodontic treatment to close the bite and adjust the incisor relationship, and surgical augmentation of hard and soft tissue in the premaxilla (if needed) accompanied or followed by implant placement.

- Surgical maxillary impaction followed by orthodontic treatment to close the bite and adjust the incisor relationship, and surgical augmentation of hard and soft tissue in the premaxilla (if needed) followed by a toothsupported fixed partial denture.

- Tooth-supported fixed partial denture with prosthetic gingival reconstruction.

- Removable partial denture restoring missing hard and soft tissues.

Because the patient did not want to undergo any surgical or orthodontic treatment due to financial and time constraints, she preferred fixed prosthesis as a treatment option, excluding other modalities.

The diagnostic cast was duplicated using light viscosity addition silicone impression material (Elite ${ }^{\circledR}$ Model, Zhermark Inc) and the impression was poured using dental stone (Elite Rock, Zhermark Inc). Afterwards, a completed diagnostic preparation of abutments (Figures 3 and 4) and waxup of the teeth (S-U-Shade-Set wax, Number 5 Intensive-white, Schuler-Dental, Ulm, Germany) and gingiva (modeling wax, Dentsply International, York, PA) were undertaken.

The diagnostic waxup of the proposed final bridge was duplicated using light viscosity addition silicone impression material (Elite Model). The impression was then poured in dental stone (Elite Rock), and a silicone index (Hydrorise Heavy, Zhermack Inc) was fabricated on this new duplicated cast.

After analyzing the diagnostic waxup and the amount of tooth preparation needed to align the upper anterior teeth in a relatively acceptable esthetic relationship to the lower ones,

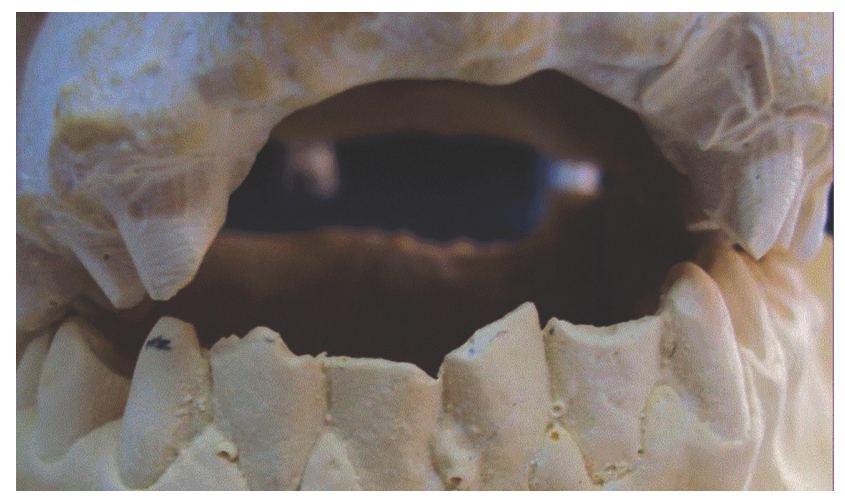

Figure 3 Frontal view of diagnostic preparation for abutments. 


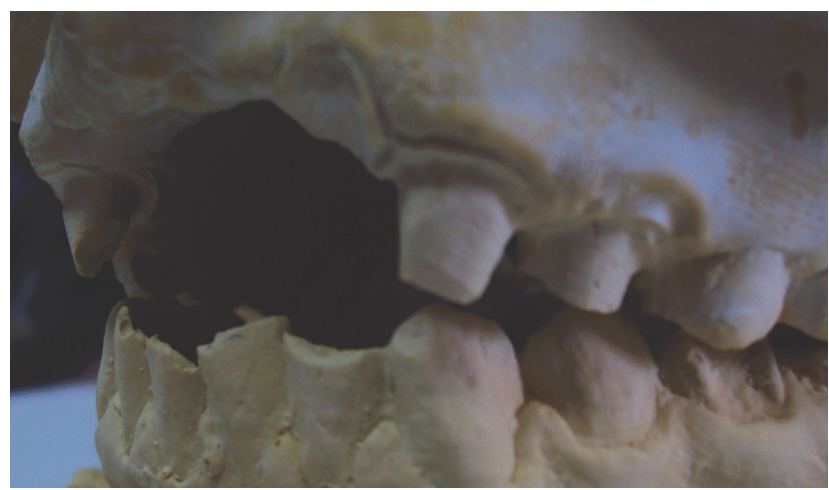

Figure $\mathbf{4}$ Lateral view of diagnostic preparation for abutments.

it was decided to extract the maxillary right central incisor and maxillary left lateral incisor, and undertake elective endodontic treatment for the maxillary right first premolar, maxillary right canine, maxillary left canine, and maxillary left first premolar.

The Maxillary canines and first premolars were endodontically treated after extraction of the maxillary right central incisor and maxillary left lateral incisor (Figures 5 and 6). Subsequently, the abutment teeth (the Maxillary canines and first premolars) were prepared in a conventional manner using diamond burrs. Margins were $1.2 \mathrm{~mm}$ wide and placed $1.0 \mathrm{~mm}$ subgingivally (Figure 7). An alginate (Orthoprint) impression of the prepared abutments was made and poured using stone (Elite Rock) to check up the preparations and to fabricate a temporary bridge (Figure 8).

The silicone index made on a duplicated cast of diagnostic waxup was placed on the cast of the prepared abutments to

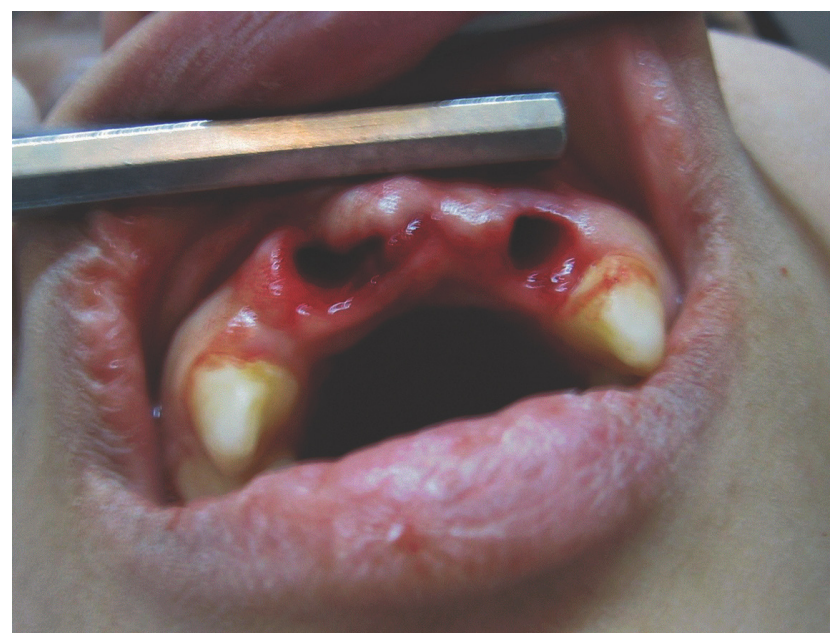

Figure 5 Extraction of maxillary right central incisor and maxillary left lateral incisor.

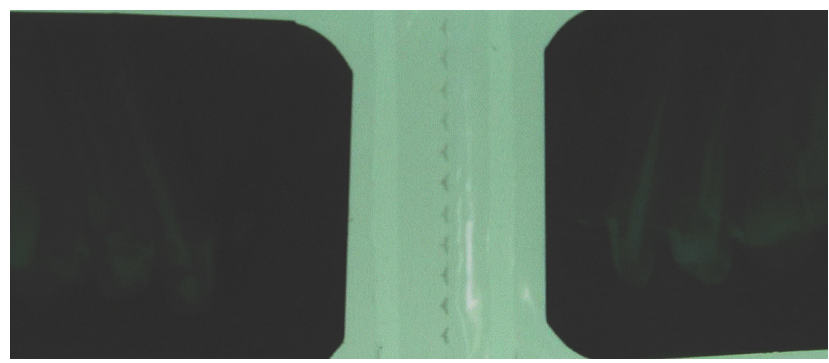

Figure 6 Postoperative periapical radiograph for maxillary right first premolar, maxillary right canine, maxillary left canine, and maxillary left first premolar.

verify the adequacy of tooth preparation for porcelain fused to metal restoration, and then to make the temporary bridge. The cast was coated with a separating medium (COE SEP ${ }^{\mathrm{TM}}$, GC Lab Technologies Inc, Lockport, IL), then a tooth-colored acrylic resin (Jet Repair Acrylic, Lang Dental Manufacturing Co, Wheeling, IL) was mixed and placed in the index and positioned on the cast. A rubber band was wrapped around the index and cast assembly. When the resin was set, the index and temporary bridge were removed from the cast (Figure 9). The margins of the temporary bridge were refined, the gingival side of the pontic area was cut back to the needed length, and the contour of the missing teeth was based on esthetic guidelines for tooth proportions. ${ }^{3}$ Gingival-colored acrylic resin (Lucitone $199^{\circledR}$, Dentsply International) was added to the gingival side of the pontic area using a brushing technique (Figure 10). After polymerization of the acrylic resin, the temporary bridge was finished, polished, and tried in the patient's mouth to verify fit, marginal adaptation, and occlusion (Figure 11).

The final impression of the prepared abutments was made using a double-stage technique with heavy and light body polyvinylsiloxane impression material (Hydrorise Heavy and Wash, Zhermack Inc). The temporary bridge was then cemented with a zinc oxide eugenol-based temporary cement (TempBond $^{\circledR}$, Kerr Corporation, Orange, CA). The casting

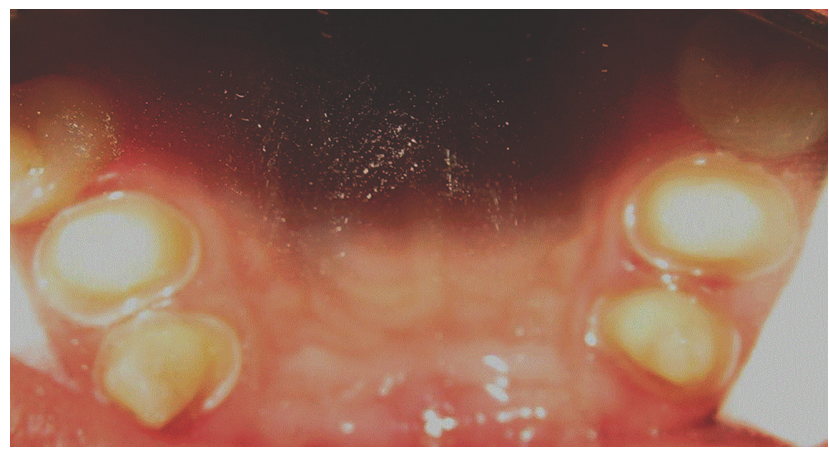

Figure 7 Abutments after preparation. 


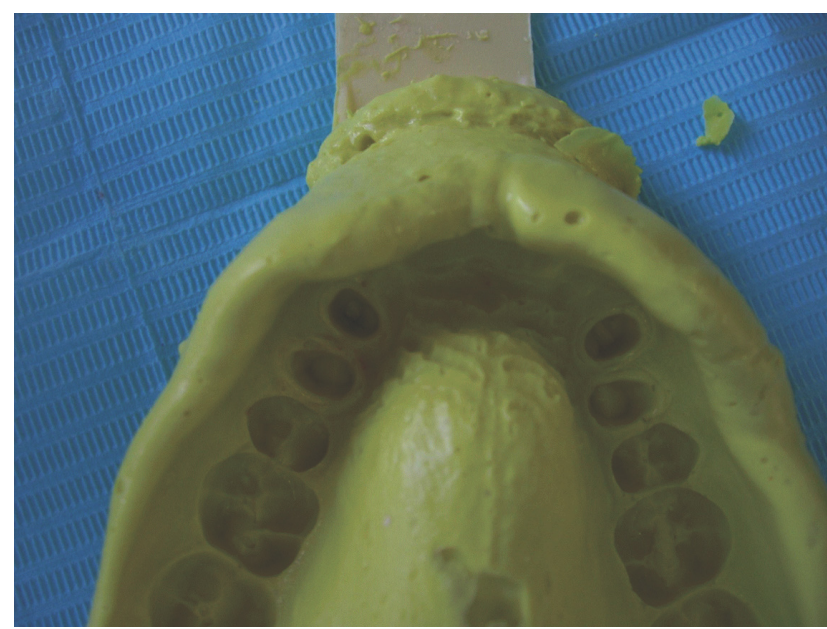

Figure 8 Alginate checkup impression after abutment preparation.

try-in was performed one week after the impression was made, and the completed porcelain fused to the metal fixed partial denture was cemented one week after the casting try-in using TempBond (Figure 12). Definitive cementation was performed using glass ionomer cement after one month (GC Fuji I ${ }^{\circledR}$, GC America Inc, Alsop, IL), as shown in Figure 13. The patient was recalled after 6 months for clinical evaluation.

\section{Discussion}

Gingival defects may be treated using a surgical or prosthetic approach. Alternatives to restore defects and a deficient edentulous span today should include prosthetic gingival restoration as an integral part of the overall esthetic reconstructive options considered. ${ }^{2,4-7}$

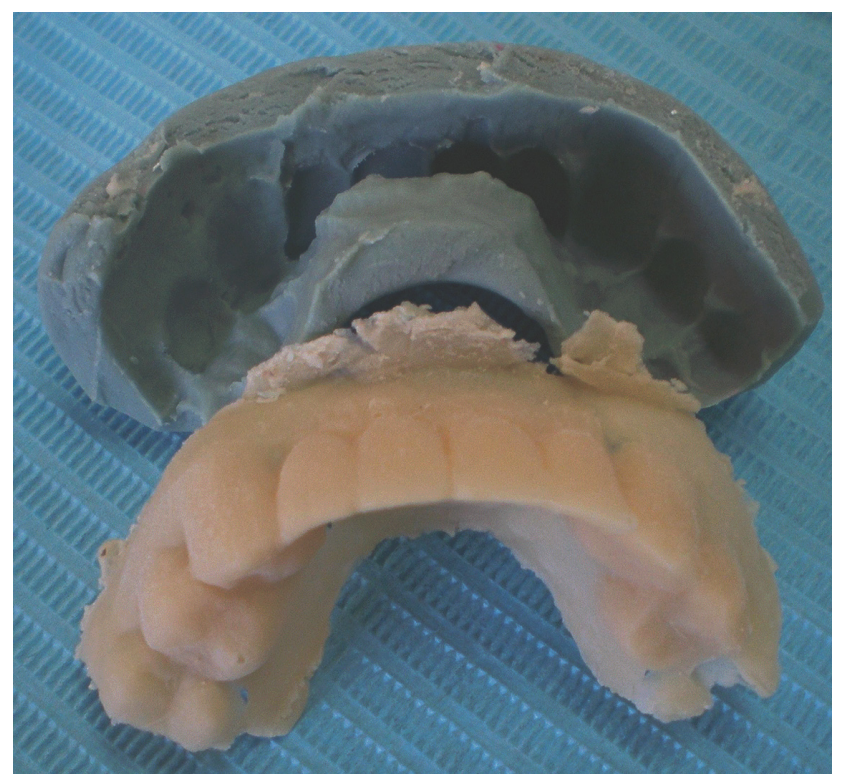

Figure 9 Temporary bridge before adding gingival porcelain.

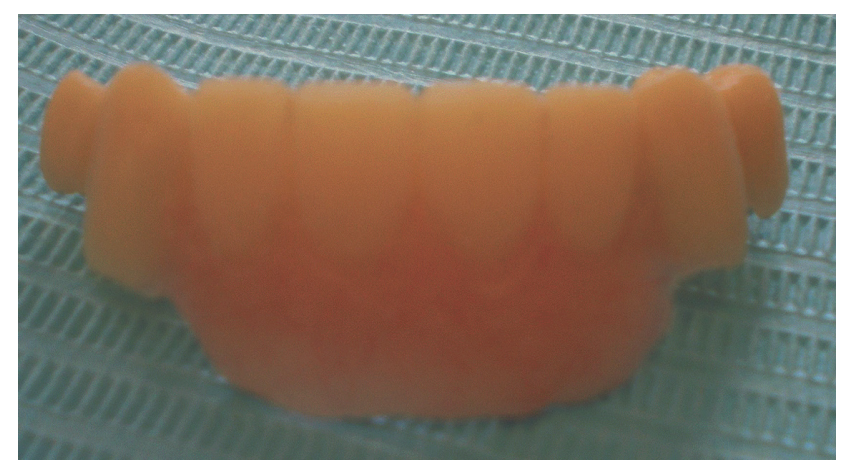

Figure 10 Temporary bridge ready for placement.

To re-establish natural crown ratios and natural gingival profiles in complex situations, artificial gingival restoration can reduce the necessity for technique-sensitive surgical procedures. It also increases intraoral comfort because of the smooth uniform interface between the prosthetic gingiva and the remaining tissues, thereby simplifying and reducing the cost and duration of treatment. ${ }^{7,8}$

The diagnostic waxup is critical when the replacement of missing teeth is esthetically challenging. The waxup provides a matrix for fabrication of provisional restoration and also a blueprint for dental positioning and adjustment of the axes of the teeth. ${ }^{9}$

Provisional restoration provides a second opportunity for the dentist to test the restoration design after the diagnostic waxup. The provisional plays several roles in the treatment process. It is used to show the patient how this kind of restoration behaves and to obtain patient approval before definitive restoration is fabricated. Phonetics are tested with the provisional, and the patient and dentist can test hygiene procedures with the provisional in place to check ease of maintenance. ${ }^{10}$

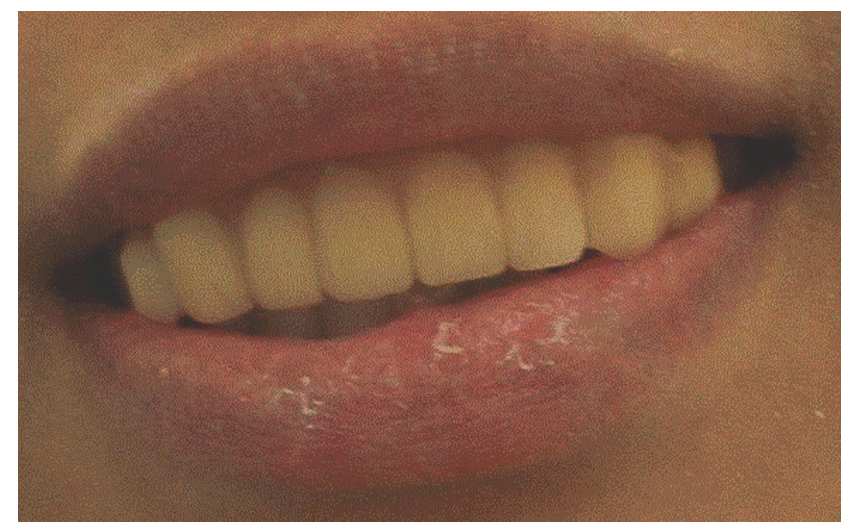

Figure I I Temporary bridge being tried in patient's mouth. 


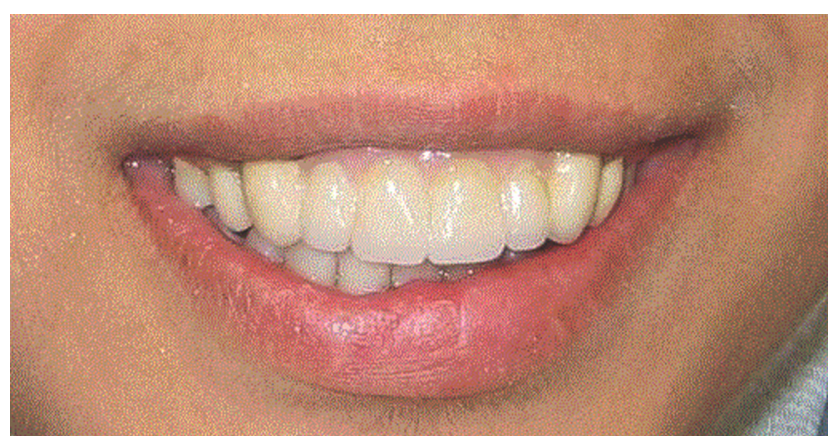

Figure 12 Definitive restoration is luted with interim luting agent.

In the present case, the final fixed prosthesis was fabricated with the teeth in their ideal position without following the current position of the alveolar ridge. Ideal teeth relationship principles were used to position the upper teeth in a normal relationship with the lower arch. Guidelines for complete denture teeth setting, including the ideal distance between incisive papillae and the labial surface of the central incisors (7-8 $\mathrm{mm}$ ), were also used from the waxup procedure through to the final restoration. ${ }^{5}$ In this clinical case, use of gingival porcelain to restore missing tissue volumes met the patient's

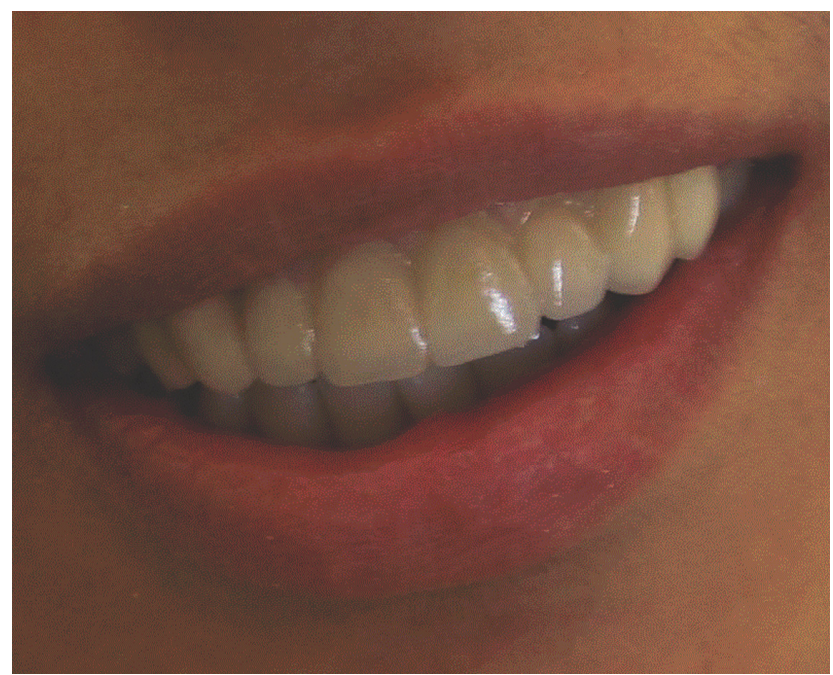

Figure 13 Definitive restoration after permanent cementation. expectations with a noninvasive treatment and a reduced cost and time needed for the procedure.

\section{Disclosure}

The authors report no conflicts of interest in this work.

\section{References}

1. Coachman C, Salama M, Garber D, Calamita M, Salama H, Cabral G Prosthetic gingival reconstruction in a fixed partial restoration. Part 1: Introduction to artificial gingival as an alternative therapy. Int J Periodontics Restorative Dent. 2009;29:471-477.

2. Hannon SM, Colvin CJ, Zurek DJ. Selective use of gingival-toned ceramics: case reports. Quintessence Int. 1994;25:233-238.

3. Kay HB. Esthetic considerations in the definitive periodontal prosthetic management of the maxillary anterior segment. Int $J$ Periodontics Restorative Dent. 1982;2:45-49.

4. Barzilay I, Irene T. Gingival prosthesis - a review. J Can Dent Assoc. 2003;69:74-78.

5. Priest GF, Lindke L. Gingival-colored porcelain for implant - supported prostheses in the aesthetic zone. Pract Periodontics Aesthet Dent. 1998;10:1231-1240.

6. Tallents RH. Artificial gingival replacements. Oral Health. 1983;73: 37-40.

7. Gracia LT, Verrett RG. Metal-ceramic restorations - custom characterization with pink porcelain. Compend Contin Educ Dent. 2004;25:242,244,246.

8. Behrend DA. The design of multiple pontics. J Prosthet Dent 1981;46:634-638

9. Salama M, Coachman C, Garber D, Calamita M, Salama H, Cabral G. Prosthetic gingival reconstruction in the fixed partial reconstruction. Part 2: Diagnosis and treatment planning. Int J Periodontics Restorative Dent. 2009;29:573-581.

10. Coachman C, Salama M, Garber D, Calamita M, Salama H, Cabral G. Prosthetic gingival reconstruction in fixed partial restorations. Part 3: Laboratory procedures and maintenance. Int J Periodontics Restorative Dent. 2010;30:19-29.
Clinical, Cosmetic and Investigational Dentistry

\section{Publish your work in this journal}

Clinical, Cosmetic and Investigational Dentistry is an international, peer-reviewed, open access, online journal focusing on the latest clinical and experimental research in dentistry with specific emphasis on cosmetic interventions. Innovative developments in dental materials, techniques and devices that improve outcomes and patient satisfac-

\section{Dovepress}

tion and preference will be highlighted. The manuscript management system is completely online and includes a very quick and fair peerreview system, which is all easy to use. Visit http://www.dovepress. com/testimonials.php to read real quotes from published authors. 